\title{
ФАКТОРЫ НАЛОГОВОГО ПОВЕДЕНИЯ В СФЕРЕ ПОДОХОДНОГО НАЛОГООБЛОЖЕНИЯ
}

\author{
И.А. Майбуров, Ю.Е. Лабунец**
}

\begin{abstract}
Проведена систематизация факторов влияния на налоговое поведение в сфере подоходного налогообложения. Рассмотрены модели налогового поведения. Методами эмпирического обобщения и конкретизации определены основные факторы влияния на налоговое поведение законопослушного налогоплательщика и налогоплательщика, уклоняющегося от подоходного налогообложения.
\end{abstract}

Ключевые слова: подоходное налогообложение, моделирование, поведение налогоплательщика.

JEL-классификация: D89, H26, H39, H87.

DOI: $10.46782 / 1818-4510-2021-2-5-13$

Материал поступил 22.03.2021 2.

Поступления от подоходного налогообложения составляют значительную часть налоговых поступлений в бюджетные системы многих стран. Их значимость для государственного развития сложно переоценить. Научные исследования налогового поведения в области подоходного налогообложения являются одной из приоритетных стратегических задач развития и совершенствования национальных налоговых систем.

В экономической литературе нет единого определения того, что именно является налоговым поведением. Ученые T.O. Weber, J. Fooken, B. Herrmann (2014) отмечают, что в целом соблюдение налогового законодательства определяется как отсутствие уклонения от уплаты налогов (tax evasion). В трудах российских и зарубежных ученых понятие «налоговое поведение» представляется как часть экономического поведения хозяйствующего субъекта, связанного с уплатой обязательных платежей в бюджет и взаимодействием налогопла-

* Исследование выполнено при финансовой поддержке РФФИ в рамках научно-исследовательского проекта №19-010-00365A. тельщика с налоговыми органами в соответствии с налоговым законодательством.

Налоговое поведение хозяйствующего субъекта неоднородно. Его разновидности исследуют ученые-экономисты, юристы, психологи, социологи, философы. Н.Н. Лепа и А.Ф. Дасив (2009) сформировали классификацию видов налогового поведения по различным признакам: форма осуществления, соблюдение налогового законодательства, рациональность и компетентность налогоплательщиков, виды налогов, социальная значимость, реализация прав и свобод, возможность предвидения, вид уклонения от уплаты налогов, направленность действий, степень общественной опасности.

Относительно налогового поведения в области подоходного налогообложения следует отметить, что подоходный налог в каждой стране имеет свои особенности, обусловленные историческими, политическими, экономическими и иными факторами. При этом научные исследования в области подоходного налогообложения могут приводить к различным результатам относительно значимых факторов влияния на налоговое поведение. В связи с этим

** Майбуров Игорь Анатольевич (i.a.mayburov@urfu.ru), доктор экономических наук, профессор, Уральский федеральный университет им. первого Президента России Б.Н. Ельцина (г. Екатеринбург, Россия);

Лабунец Юлия Евгеньевна (iulia.labunets@urfu.ru), Уральский федеральный университет им. первого Президента России Б.Н. Ельцина (г. Екатеринбург, Россия). 
представляются актуальными систематизация и обзор научных исследований налогового поведения в области подоходного налогообложения для определения общих факторов его влияния как на уровень соблюдения налогового законодательства, так и на уровень уклонения от подоходного налогообложения.

Согласно исследованиям (Hashimzade, Myles, Page, Rablen, 2014), в целях подоходного налогообложения возможности для уклонения от работы в большинстве форм занятости весьма ограничены. Вычет подоходного налога у источника и отчетность третьих лиц делают уклонение от уплаты налога очень трудным и даже неневозможным. Напротив, доход, полученный от самозанятости или от предпринимательской деятельности, не облагается налогом у источника и может иметь ограниченную отчетность перед третьими лицами. Это дает возможность уклоняться от уплаты налогов при самозанятости. Настоящее исследование проводилось на примере налогового поведения самозанятых лиц и индивидуальных предпринимателей в области подоходного налогообложения.

Систематизируем факторы влияния на налоговое поведение в области подоходного налогообложения.

Гипотеза нашего исследования заключается в том, что на уровень соблюдения налогового законодательства, главным образом, влияют неэкономические факторы, а на уровень уклонения от подоходного налогообложения - экономические.

\section{Методика исследования}

Методический аппарат исследования базируется на общенаучных и частных методах познания: сравнительного анализа, систематизации, эмпирического обобщения и конкретизации.

Методология исследования заключается в подборке научных исследований, содержащихся в базах данных Scopus, Web of Science, Researchgate, SSRN. Выбор научных исследований осуществлялся за период с 1972 по 2020 г. по ключевым словам: «уклонение от налогообложения» (tax evasion), «соблюдение налогового законо- дательства» (tax compliance) в области подоходного налогообложения самозанятых лиц и индивидуальных предпринимателей. В сформированной выборке научных исследований определялись основные факторы, характер их влияния на налоговое поведение в области подоходного налогообложения.

\section{Теоретические аспекты моделирования налогового поведения}

Задача обеспечения эффективного и результативного процесса управления налоговым поведением заключается в установлении основных факторов, влияющих на налоговое поведение хозяйствующих субъектов.

Зависимость налогового поведения от изменения того или иного фактора наилучшим образом может быть описана методом моделирования, позволяющим в условиях, максимально приближенных к реальной действительности, изучить стратегии поведения объектов исследования в многофакторной среде.

Многообразие существующих в настоящее время моделей налогового поведения можно условно разделить на три типа (рис. 1): модели налогового поведения, основанные на классической модели (Allingham, Sandmo, 1972), поведенческой экономики, а также модели, в основе которых лежит институциональная теория поведения экономических агентов.

Одной из первых моделей налогового поведения хозяйствующих субъектов является модель уклонения от уплаты налогов в экономике, созданная учеными M.G. Allingham и A. Sandmo. Ее формирование осуществлялось с помощью лабораторного эксперимента, применяемого для исследования причин уклонения от уплаты на примере подоходного налога. Основой данной модели стала теория экономической преступности (Becker, 1968). Это классическая модель рационального выбора налогоплательщика, принимающего решение об уклонении в условиях неопределенности. В результате проведенного лабораторного эксперимента с учетом допущений M.G. Allingham и A. Sandmo (1972) установили такие вне- 


\begin{tabular}{|c|c|c|}
\hline \multicolumn{3}{|c|}{ Теория ожидаемой полезности } \\
\hline$\nabla$ & $\nabla$ & $\nabla$ \\
\hline $\begin{array}{c}\text { Традиционная классическая модель } \\
\text { налогового поведения, основанная } \\
\text { на рациональном выборе }\end{array}$ & $\begin{array}{l}\text { Модели налогового поведения } \\
\text { в поведенческой экономике }\end{array}$ & $\begin{array}{c}\text { Модели налогового поведения, } \\
\text { основанные на институциональной } \\
\text { теории поведения экономических } \\
\text { агентов }\end{array}$ \\
\hline$\nabla$ & $\nabla$ & \multirow[b]{2}{*}{ Оппортунист-максимизатор } \\
\hline $\begin{array}{c}\text { Моделирование налогового } \\
\text { поведения, дополняющее } \\
\text { традиционную классическую модель }\end{array}$ & $\begin{array}{c}\text { Модели, изучающие влияние неэкономических } \\
\text { факторов }\end{array}$ & \\
\hline $\begin{array}{c}\text { Модели, уточняющие } \\
\text { и дополняющие фактор издержек } \\
\text { уклонения }\end{array}$ & $\begin{array}{c}\text { Модели, основанные на теории } \\
\text { ограниченной рациональности } \\
\text { (Simon, 1955) }\end{array}$ & $\begin{array}{l}\text { Оппортунист с ограниченной } \\
\text { формой рациональности }\end{array}$ \\
\hline \multirow{2}{*}{$\begin{array}{c}\text { Модели, уточняющие } \\
\text { и дополняющие фактор доходов } \\
\text { налогоплательщика от уклонения } \\
\text { от налогов }\end{array}$} & $\begin{array}{c}\text { Модели, основанные на теории } \\
\text { перспектив (Kahneman, Tversky, 1979) }\end{array}$ & $\begin{array}{c}\text { Законопослушный тип } \\
\text { налогоплательщика }\end{array}$ \\
\hline & $\begin{array}{c}\text { Модели, основанные на ранговой } \\
\text { теории ожидаемой полезности } \\
\text { (Quiggin, 1982) }\end{array}$ & $\begin{array}{c}\text { Законопослушный тип } \\
\text { налогоплательщика } \\
\text { с ограниченной } \\
\text { рациональностью }\end{array}$ \\
\hline $\begin{array}{l}\text { и дополняющие фактор } \\
\text { штрафных санкций }\end{array}$ & $\begin{array}{c}\text { Модели, основанные на неаддитивной } \\
\text { вероятности (Schmeidler, 1989) }\end{array}$ & \\
\hline $\begin{array}{c}\text { Модели, уточняющие } \\
\text { и дополняющие фактор } \\
\text { вероятности проведения } \\
\text { налоговых проверок } \\
\end{array}$ & $\begin{array}{c}\text { Модели, основанные на } \\
\text { гиперболическом дисконтировании } \\
\text { (Laibson, 1997) }\end{array}$ & \\
\hline $\begin{array}{c}\text { Модели, дополняющие } \\
\text { классическую модель новыми } \\
\text { экономическими факторами }\end{array}$ & $\begin{array}{c}\text { Классическая бихевиористская модель } \\
\text { уклонения от уплаты налогов } \\
\text { (Spicer, Becker 1980) }\end{array}$ & \\
\hline
\end{tabular}

Рис.1. Модели налогового поведения

Источник. Авторская разработка.

шние экономические факторы, влияющие на уклонение от уплаты налогов, как: вероятность аудита; ставки штрафов; налоговые ставки. Стандартные выводы из данной модели заключаются в том, что каждый налогоплательщик склонен к уклонению от налогообложения и он уплачивает налоги в том числе потому, что боится быть пойманным и наказанным.

В дальнейшем ряд зарубежных и отечественных ученых пытались расширить эту модель посредством учета особенностей действия различных видов налогов, характера штрафных санкций и функций полезности индивидов, коррупции. Была также предложена модель коррупционного равновесия, поддерживаемого неоптимальной налоговой политикой. В 2004 г. интерпретацию модели (Allingham, Sandmo, 1972) предложили В. Вишневский и А. Веткин (2004), предположив при этом следующее: на полезность уклонения налогоплательщика влияют не отдельные налоги, а вся сово- купность, действие которой выражается через среднюю ставку налога или налоговый коэффициент. В отличие от классической модели размер сокрытого штрафа представлен как функция от сокрытого налога, а не от незадекларированного дохода. Кроме того, указанными учеными дополнительно учтено влияние трансакционных издержек (комиссионные вознаграждения посредникам за оказание услуг по уклонению и внутренние издержки компаний, связанные с необходимостью ведения двойного учета в процессе уклонения от налогообложения).

В.И. Цуриков (2007) в своих исследованиях предпринял попытку учесть не только трансакционные издержки и комиссионные, уплачиваемые посреднику, но и фактор коррупции.

Становление и развитие поведенческой экономики, в рамках которой наряду с методами экспериментальной экономики широко применяются междисциплинарные 
подходы и методы для анализа индивидуальных или групповых решений, а также факторов, их определяющих, вызвали научные исследования, результатом которых стало формирование моделей налогового поведения, углубляющих теорию ожидаемой полезности.

Кроме моделей налогового поведения в рамках поведенческой экономики, необходимо отметить модели налогового поведения, в основе которых лежат допущения модели институционального поведения хозяйственных субъектов. Построение модели налогового поведения экономического человека происходит через использование таких важнейших поведенческих концепций неоинституциональной теории, как рациональность и оппортунистическое поведение, и выделение превалирующих теоретических типов налогового поведения на основе сочетания различных форм рациональности и степеней эгоистичности в следовании своим интересам. В основе институциональной модели налогового поведения лежит допущение ограниченной рациональности при выборе налогоплательщика между уплатой налогов и их минимизацией.

Следует отметить, что все типы моделей актуальны в настоящее время, при этом необходимы дальнейшие научные исследования в целях повышения их реалистичности и построения долгосрочных прогнозов налогового поведения.

\section{Факторы, оказывающие влияние на налоговое поведение в области подоходного налогообложения}

В настоящее время научные исследования в области моделирования налогового поведения установили влияние на него множества различных факторов.

В целом все многообразие известных факторов условно можно разделить на две категории:

- экономические факторы (издержки: налоговая ставка, величина санкций, вероятность налоговой проверки; выгоды);

- неэкономические факторы (внутренние: мотивы, эмоции, убеждения; внешние: социальные нормы, институты, обычаи, традиций).
Влияние экономических и административных факторов обосновано в модели поведения (Allingham, Sandmo A., 1972).

Неэкономические факторы наряду с экономическими и административными оказывают существенное воздействие на налоговое поведение хозяйствующих субъектов по выполнению ими налоговых обязательств.

В отношении налогового поведения в области подоходного налогообложения были изучены исследования ученых разных стран за период с 1972 по 2020 г. Одна из стандартных интерпретаций влияния фактора вероятности налоговых проверок на налоговое поведение заключается в том, что налогоплательщики реагируют на информацию об инструментах налогового принуждения и, в соответствии с положениями модели M.G. Allingham, A. Sandmo (1972), сокращают свое уклонение, чтобы оптимизировать налоговое поведение. В научных исследованиях налогового поведения в области подоходного налогообложения экономический фактор вероятности налоговых проверок также присутствует. Так, J. Slemrod, M. Blumenthal, C. Christian (2001) показали, что американские самозанятые (случайным образом назначенные для получения письма из Министерства доходов штата Миннесота о принудительном исполнении налоговых обязательств) сообщили о более высоком доходе в своих налоговых декларациях. В дальнейшем научные исследования этих ученых, а также D. Pomeranz и J. Vila-Belda (2019) подтвердили, что подобные информационные сообщения о налоговом правоприменении оказывают положительное влияние на соблюдение налогового законодательства.

Большинство рассмотренных научных исследований подтверждают положительное влияние вероятности налоговых проверок на налоговое поведение в области подоходного налогообложения, при этом необходимо отметить, что ученые J. Alm, A. Enami, M. McKee (2020), не отрицая положительного влияния вероятности налоговых проверок, по результатам своего анализа внесли уточнение о влиянии данного фактора. Так, в ходе проведения лабораторных экспериментов в пяти отдельных ис- 
следованиях с участием в общей сложности 278 студентов они выполнили 8340 индивидуальных наблюдений. Было установлено, что только $2 / 3$ общего количества испытуемых, реагируя на повышение вероятности налоговой проверки, увеличивают уровень соблюдения законодательства в области подоходного налогообложения. Оставшаяся 1/3 испытуемых в результате исследования распределена следующим образом: 1/6 часть тестируемых не реагировала на повышение вероятности налоговой проверки, еще 1/6 их часть, наоборот, отвечала уменьшением уровня соблюдения законодательства в области подоходного налогообложения.

При этом под влиянием увеличения частоты налоговых проверок уровень уклонения от подоходного налогообложения уменьшается. Часть налогоплательщиков, уходящих от уплаты налогов, согласно исследованиям J. Lorenz (2019), переходит на легальную оптимизацию налогообложения. Работа Y. Ma, S. Shan, W. Xu (2019) также подтверждает, что число уклонений от уплаты налогов может быть уменьшено путем увеличения штрафа, а также частоты налоговых проверок. Кроме того, согласно исследованию E. D’Agosto, M. Manzo, S. Pisani, F.M. D'Arcangelo (2018), налоговые проверки (камеральный, выездной контроль) и их последовательное сочетание несут положительный эффект сдерживания от уклонения в основном в первые несколько налоговых периодов после проведения данных проверок.

Проведенные эксперименты влияния механизма налогообложения на налоговое поведение показали, что при изменении режима налогообложения с плоской шкалы на прогрессивную (Heinemann, Kocher, 2013) уровень уклонения от уплаты налога увеличивается по мере увеличения дохода (Becker, Büchner, Sleeking, 1987; Anderhub, Giese, Gth, Hoffmann, Otto, 2001) и по мере увеличения ставки налога (Alm, Jackson, McKee, 1992).

M.W. Spicer и L.A. Becker (1980) в своих исследованиях применяли различные налоговые ставки для участников эксперимента и пришли к выводу, что больше всего уклоняются от уплаты налогов те, у кого самая высокая налоговая нагрузка.
F. Heinemann и M.G. Kocher (2013) использовали метод игр. Объектам исследования - участникам их эксперимента устанавливался доход, который был частично связан с измеряемыми способностями, а частично - со стохастическими. В течение 10 периодов ученые применяют в эксперименте либо пропорциональный, либо прогрессивный налог. Через 10 периодов происходит смена режима. Те объекты исследования, у которых налоговое бремя увеличивается в результате смены механизма налогообложения, уклонялись от большего количества налогов. В целом, был сделан вывод, что переход к прогрессивному налогообложению увеличивает вероятность уклонения от уплаты налогов. P. Doerrenberg и D. Duncan (2014) в исследованиях отмечают, что участники эксперимента с более низкой способностью зарабатывать, как правило, уклоняются от большего количества налогов.

Помимо фактора объективной оценки вероятности налоговой проверки необходимо отметить влияние на действия индивида субъективной оценки такой вероятности. Теория рангово-зависимой ожидаемой полезности (Quiggin, Wakker, 1994) использует особую схему взвешивания для преобразования объективной вероятности событий в субъективную, она была применена при исследовании вопроса об уклонении от уплаты налогов (Arcand, Graziosi, 2005; Bernasconi, 1998; Kahneman, Tversky, 1979).

M.F. Castro, I. Rizzo (2014) классифицируют объекты исследования по их производительности труда и по величине дохода в зависимости от вида деятельности. Установлено, что если объекты исследования с невысокой величиной дохода и низкой производительностью труда платят налоги по высоким ставкам («вертикальное неравенство»), то существенной разницы в частоте уклонений от уплаты налогов нет. Но при использовании различных налоговых ставок («горизонтальное неравенство») в группе объектов исследования с низким уровнем дохода и низкой производительностью труда наблюдались значительные расхождения в уровне уклонений от налогообложения. 
В результате исследования фактора влияния способа получения дохода на дальнейшее налоговое поведение сформировалось два взаимосвязанных вывода.

1. Исполнение налогоплательщиком обязательств по исчислению и уплате налога не зависит от источника полученного им дохода (Durham, Manly, Ritsema, 2014).

2. В исследованиях уровней уклонения от налогообложения среди работающих и безработных отмечено, что чем больше индивид прикладывает усилий для получения дохода, тем больше его склонность к уклонению от налогообложения (Bühren, Kundt, 2014).

B. Fortin, G. Lacroix, M.C. Villeval (2007) при исследовании влияния социальных норм и институтов на налоговое поведение обращают внимание на так называемые «эффекты сверстников», или «эффекты социальных взаимодействий» в налоговом поведении. При этом они отмечают, что склонность индивида к уклонению может действительно варьироваться в зависимости от поведения группы (эндогенные взаимодействия), а также от экзогенных характеристик членов группы (экзогенные взаимодействия). Кроме того, коррелированные результаты уклонения от уплаты налогов не обязательно должны быть итогом взаимозависимого поведения. Действительно, члены данной группы могут вести себя аналогично, поскольку они обладают схожими индивидуальными характеристиками или сталкиваются с подобными институциональными условиями (коррелированные эффекты). По результатам экспериментов указанные ученые пришли к выводу, что наибольшее влияние оказывают социальные нормы и институты на налоговое поведение при согласованности индивидуальных и групповых реакций, в противном случае индивид в налоговом поведении будет полагаться на собственное восприятие. При этом воспринимаемое несправедливым налогообложение может привести к увеличению числа уклонений от уплаты налогов.

Субъективное ощущение вероятности налоговой проверки может быть выше объективной вероятности проверки. Значение, придаваемое социальным обычаям, различается в зависимости от профессии. Эти факторы в совокупности приводят к более низкому уровню соблюдения налогового законодательства в более рискованной профессии. Поведение в разных профессиональных группах отличается, и это подкрепляется развитием групповых установок и убеждений.

В научных исследованиях влияния социальных норм и институтов на налоговое поведение обоснованы следующие выводы:

- социальные нормы являются более сильной защитой от сговора, чем от индивидуального уклонения от уплаты налогов (Abraham, Lorek, Richer, Wrede, 2017);

- уклонение от уплаты налогов тем меньше, чем больше общественных благ участники получают «в обмен» на свои налоги (Alm, McClelland, Schulze, 1992);

- уклонение от уплаты налогов уменьшается, если известно, что налоговый доход будет использоваться для поддержки других участников (Bosco, Mittone, 1997).

Влиянию социальных норм на налоговое поведение посвящено исследование (Doerrenberg, Peichl, 2017). Ученые приходят к выводу, что информирование физических лиц о распространенности уклонения от уплаты налогов не повышает их желания следовать закону.

Влияние фактора морали на исполнение налоговых обязательств также подтверждено в работе (Blaufus, Hundsdoerfer, Jacob, Sünwoldt, 2016). Подчеркивание аморальности уклонения от уплаты налогов, согласно этому исследованию, имеет эффект, в то время как подчеркивание его незаконности - нет.

На решение налогоплательщиков могут оказывать влияние следующие факторы, входящие в концепцию налоговой морали: справедливость (Spicer, Becker, 1980), альтруизм (Cox, Friedman, Sadiraj, 2008), вина и стыд (Casagrande, 2015), патриотизм (Konrad, Lohse, Qari, 2017), внутренняя мотивация и честность (Alm, Bruner, McKee, 2016).

Фактор обучения самозанятых индивидов и индивидуальных предпринимателей также влияет на их дальнейшее налоговое поведение. К такому выводу пришли H. Nagel, L.R. Huber, M. van Praag, S. Goslinga (2019). Более того, обучение никак не связано с выживаемостью бизнеса, но обученные предприниматели декларируют значи- 
тельно больший доход. В исследовании (Muehlbacher, Mittone, Kastlunger, Kirchler, 2012) отмечается, что главным образом самозанятые, не имеющие представления о хозяйственном учете и механизмах налогообложения, должны быть обучены проведению налогового учета, что в дальнейшем положительно повлияет на соблюдение ими налогового законодательства.

Допущения, лежащие в основе экономического подхода к налоговой преступности в том числе в области подоходного налогообложения, могут не совпадать с представлениями об индивидуальном поведении будто индивиды только рациональны, обладают неограниченной силой воли и мотивированы исключительно узко определенными и индивидуально обоснованными финансовыми соображениями. Все эти предположения все чаще ставятся под сомнение в рамках поведенческой экономики. Мотивация людей к исполнению налогового законодательства может заключаться в превышении выгод над издержками. Кроме того, они могут неверно оценивать истинные издержки своих действий (например, в результате завышения или занижения вероятности налоговых проверок). Они могут испытывать трудности с выполнением вычислений из-за их сложности или неопределенности, быть мотивированы широким спектром факторов, включая личные интересы (узко определенные), но также и понятиями справедливости, альтруизма, взаимности, сопереживания, симпатии, доверия, вины, морали, отчуждения, патриотизма, социальными нормами, налоговой моралью, внутренней мотивацией и др. Все эти мотивации снижают степень влияния предполагаемых налоговых проверок на соблюдение налоговой дисциплины.

Таким образом, на уровень соблюдения налогового законодательства не склонными к риску налогоплательщиками в области подоходного налогообложения оказывают большее влияние неэкономические факторы. Грамотное же управление налоговыми органами проведением проверок будет сдерживать частоту уклонений от налогообложения.

\section{СПИСОК ЛИТЕРАТУРЫ (REFERENCES)}

Вишневский В., Веткин А. 2004. Уклонение от уплаты налогов и рациональный выбор налогоплательщика. Вопросы экономики. № 2. С. 96108. [Vishnevsky V., Vetkin A. 2004. Tax evasion and rational choice of the taxpayer. Voprosy ekonomiki. No 2. PP. 96-108. (In Russ.)]

Лепа Н.Н., Дасив А.Ф. 2009. Классификационная структура налогового поведения предприятий и варианты их налогового реагирования. Науковий вісник Чернігівського державного інституту економіки і управління. № 3. С. 4252. [Lepa N.N., Dasiv A.F. 2009. Classification structure of tax behavior of enterprises and options for their tax response. Naukoviy visnik Chermigivs'kogo derzhavnogo institutu ekonomiki i upravlinnya. No 3. PP. 42-52. (In Russ.)]

Цуриков В.И. 2007. Модель рационального поведения налогоплательщика. Экономика и математические методы. Т. 43. № 2. С. 3-11. [Tsurikov V.I. 2007. The model of rational behavior of the taxpayer. Ekonomika i matematicheskie metody. Vol. 43. No 2. PP. 3-11. (In Russ.)]

Abraham M., Lorek K., Richter F., Wrede M. 2017. Collusive Tax Evasion and Social Norms. International Tax and Public Finance. Vol. 24. PP. 179-197.

Anderhub V., Giese S., Güth W., Hoffmann A., Otto T. 2001. Tax Evasion with Earned Income - an Experimental Study. Public Finance Analysis. Vol. 58. Iss. 2. PP. 188-206.

Allingham M.G., Sandmo A. 1972. Income Tax Evasion: A Theoretical Analysis. Journal of Public Economics. Vol. 1. Iss. 3-4. PP. 323-338.

Alm J., Jackson B.R., McKee M. 1992. Estimating the Determinants of Taxpayer Compliance with Experimental Data. National Tax Journal. Vol. 45. No 1. PP.107-114.

Alm J., McClelland G.H., Schulze W.D. 1992. Why Do People Pay Taxes? Journal of Public Economics. No 48. Iss. 1. PP. 21-38.

Alm J., Enami A., McKee M. 2020. Who Responds? Disentangling the Effects of Audits on Individual Tax Compliance Behavior. Atlantic Economic Journal. Vol. 48. Iss. 2. No 2. PP. 147-159.

Alm J., Bruner D., McKee M. 2016. Honesty or dishonesty of taxpayer communications in an enforcement regime. Journal of Economic Psychology. Vol. 56. PP. 85-96. 
Arcand J.-L., Graziosi G.R. 2005. Tax Compliance and Rank-Dependent Expected Utility. The Geneva Risk and Insurance Review. No 30. PP. 57-69.

Becker G.S. 1968. Crime and Punishment: An Economic Approach. Journal of Political Economy. Vol. 76. PP. 169-217.

Becker W., Büchner H.J., Sleeking S. 1987. The Impact of Public Transfer Expenditures on Tax Evasion. An Experimental Approach. Journal of Public Economics. Vol. 34. Iss. 2. PP. 243-252.

Bernasconi M. 1998. Tax evasion and orders of risk aversion. Journal of Public Economics. Vol. 67. Iss. 2. PP. 123-134.

Bühren C., Kundt T.C. 2014. Does the Level of Work Effort Influence Tax Evasion? Experimental Evidence. Review of Economics. Vol. 65. Iss. 2. PP. 137-158.

Blaufus K., Hundsdoerfer J., Jacob M., Sünwoldt M. 2016. Does Legality Matter? The Case of Tax Avoidance and Evasion. Journal of Economic Behavior \& Organization. Vol. 127. PP. 182-206.

Bosco L., Mittone L. 1997. Tax Evasion and Moral Constraints: Some Experimental Evidence. Kyklos. Vol. 50. Iss. 3. PP. 297-324.

Casagrande A. 2015. The effect of competition on tax compliance: The role of audit rules and shame. Journal of Behavioral and Experimental Economics. Vol. 59. PP. 96-110.

Castro M.F., Rizzo I. 2014. Tax compliance under horizontal and vertical equity conditions: An experimental approach. International Tax and Public Finance. Vol. 21. Iss. 4. PP. 560-577.

Cox J.C., Friedman D., Sadiraj V. 2008. Revealed Altruism. Econometrica. Vol. 76. No 1. PP. 31-69.

D'Agosto E., Manzo M., Pisani S., D'Arcangelo F.M. 2018. The Effect of Audit Activity on Tax Declaration: Evidence on Small Businesses in Italy. Public Finance Review. Vol. 46. Iss. 1. PP. 29-57

Doerrenberg P., Duncan D. 2014. Distributional Implications of Tax Evasion: Evidence from the Lab. Public Finance Review. Vol. 42. Iss. 6. PP. 720-744.

Doerrenberg P., Peichl A. 2017. Tax Morale and the Role of Social Norms and Reciprocity. Evidence from a Randomized Survey Experiment. ZEW. Discussion Paper. No 17-045. 38 p.

Durham Y., Manly T.S., Ritsema C. 2014. The Effects of Income Source, Context, and Income Level on Tax Compliance Decisions in a Dynamic Experiment. Journal of Economic Psychology. No 40. PP. 220-233.

Fortin B., Lacroix G., Villeval M.-C. 2007. Tax Evasion and Social Interactions. Journal of Public Economics. Vol. 91. Iss. 11-12. PP. 2089-2112.

Heinemann F., Kocher M.G. 2013. Tax Compliance under Tax Regime Changes. International Tax and Public Finance. Vol. 20. Iss. 2. PP. 225-246.
Kahneman D., Tversky A. 1979. Prospect Theory: An Analysis of Decision under Risk. Econometrica. Vol. 47. No 2. PP. 263-291.

Konrad K.A., Lohse T., Qari S. 2017. Compliance with Endogenous Audit Probabilities. Scandinavian Journal of Economics. Vol. 119. Iss. 3. PP. 821-850.

Laibson D.I. 1997. Golden Eggs and Hyperbolic Discounting. Quarterly Journal of Economics. Vol. 112. Iss. 2. PP. 443-477.

Lorenz J. 2019. Population Dynamics of Tax Avoidance with Crowding Effects. Journal of Evolutionary Economics. Vol. 29. Iss. 2. No 3. PP. 581609.

Ma Y., Shan S., Xu W. 2019. Optimal investment and consumption in the market with jump risk and capital gains tax. Joumal of Industrial Eै Management Optimization. Vol. 15. Iss. 4. PP. 1937-1953.

Muehlbacher S. Mittone L., Kastlunger B., Kirchler E. 2012. Uncertainty resolution in tax experiments: Why waiting for an audit increases compliance. The Journal of Socio-Economics. Vol 41. Iss. 3. PP. 289-291.

Nagel H., Huber L. R., Van Praag M., Goslinga S. 2019. The effect of a tax training program on tax compliance and business outcomes of starting entrepreneurs: Evidence from a field experiment. Journal of Business Venturing. Vol. 34. Iss. 2. PP. 261-283.

Pomeranz D., Vila-Belda J. 2019. Taking State-Capacity Research to the Field: Insights from Collaborations with Tax Authorities. CEPR Discussion Papers. No 13688.

Quiggin J. 1982. A Theory of Anticipated Utility. Journal of Economic Behavior \& Organization. Vol. 3. Iss. 4. PP. 323-343.

Quiggin J., Wakker P. 1994. The axiomatic basis of anticipated utility: a claribication. Journal of Economic Theory. Vol. 64. Iss. 2. PP. 486-499.

Schmeidler D. 1989. Subjective Probability and Expected Utility Theory without Additivity. Econometrica. Vol. 57. Iss. 3. PP. 571-587.

Simon H. 1955. A Behavioral Model of Rational Choice. Quarterly Journal of Economics. Vol. 69. No 1. PP. 99-118.

Slemrod J., Blumenthal M., Christian C. 2001. Taxpayer Response to an Increased Probability of Audit: Evidence from a Controlled Experiment in Minnesota. Journal of Public Economics. Vol. 79. Iss. 3. PP. 455-483.

Spicer M.W., Becker L.A. 1980. Fiscal Inequity and Tax Evasion: An Experimental Approach. National Tax Journal. Vol. 33. Iss. 2. PP. 171-175.

Weber T.O., Fooken J., Herrmann B. 2014. Behavioural Economics and Taxation. Taxation Papers. No 41. 40 p. 
In citation: Belorusskiy Ekonomicheskiy zhurnal. 2021. No 2. PP. 5-13.

Belarusian Economic Journal. 2021. No 2. PP. 5-13.

\section{FACTORS OF TAX BEHAVIOUR IN TERMS OF INCOME TAXATION}

\section{Igor Mayburov ${ }^{1}$, Yulia Labunets ${ }^{1}$}

Author affiliation: ${ }^{1}$ Ural Federal University named after the First President of Russia B.N. Yeltsin (Yekaterinburg, Russia).

Corresponding author: Igor Mayburov (i.a.mayburov@urfu.ru).

ABSTRACT. The article systemizes factors that affect tax behavior in terms of income taxation. Patterns of tax behaviour are considered. Methods of empirical generalization and specification are used to define key factors that affect tax behavior of law-abiding taxpayer and of those dodging income taxes.

KEYWORDS: income taxation, modeling, taxpayer behavior.

JEL-code: D89, H26, H39, H87.

DOI: $10.46782 / 1818-4510-2021-2-5-13$

Received 22.03.2021 